\title{
Experimental reinfection of BALB/c mice with different recombinant type I/III strains of Toxoplasma gondii: involvement of IFN- $\gamma$ and IL-10
}

\author{
Geane Peroni Brandão1, Maria Norma Melo', Ricardo Tostes Gazzinelli², Braulia Costa Caetano², \\ Adriana Melo Ferreira1, Letícia Azevedo Silva', Ricardo Wagner Almeida Vitor ${ }^{1 /+}$ \\ ${ }^{1}$ Departamento de Parasitologia ²Departamento de Bioquímica e Imunologia, Instituto de Ciências Biológicas, \\ Universidade Federal de Minas Gerais, Av. Antonio Carlos 6627, 31270-901 Belo Horizonte, MG, Brasil
}

To assess reinfection of BALB/c mice with different Toxoplasma gondii strains, the animals were prime infected with the non-virulent D8 strain and challenged with virulent recombinant strains. Thirty days after challenge, brain cysts were obtained from surviving BALB/c mice and inoculated in Swiss mice to obtain tachyzoites for DNA extraction and PCR-RFLP analysis to distinguish the different $\mathrm{T}$. gondii strains present in possible co-infections. AntiToxoplasma immune responses were evaluated in D8-primed BALB/c mice by detecting IFN- $\gamma$ and IL-10 produced by $T$ cells and measuring immunoglobulin levels in serum samples. PCR-RFLP demonstrated that BALB/c mice were reinfected with the EGS strain at 45 days post prime infection (dpi) and with the EGS and CH3 strains at 180 dpi. High levels of IFN- $\gamma$ were detected after D8 infection, with no significant difference between 45 and 180-day intervals. However, higher IL-10 levels and higher plasmatic IgGI and IgA were detected from samples obtained 180 days after infection. BALB/c mice were susceptible to reinfection with different recombinant $\mathrm{T}$. gondii strains and this susceptibility correlated with enhancement of IL-10 production.

Key words: experimental toxoplasmosis - reinfection - recombinant strains - cytokine

Infection with Toxoplasma gondii is usually asymptomatic in immunocompetent individuals but may lead to severe neurological symptoms in HIV-positive patients and in congenitally infected foetuses (Gellin \& Soave 1992). During the early phase, toxoplasmosis resistance is related to the initial production of IL-12 and IFN- $\gamma$ by natural killer cells (Buzoni-Gatel et al. 2006). During the chronic phase, TH1 CD4+ cells and CD8+ cytotoxic $\mathrm{T}$ lymphocytes are vital in producing protective immunity and long-term survival (Gazzinelli et al. 1992). The protective effect of these cells is explained by their ability to produce IFN- $\gamma$ (Suzuki et al. 1989) and by their cytotoxic activity against tachyzoites or cells infected with the parasite (Subauste et al. 1991).

Primary infection with $T$. gondii is believed to lead to a life-long immunity, preventing host reinfection (Filisetti \& Candolfi 2004). Nonetheless, cases of congenital toxoplasmosis in the chronic phase have been reported in immunocompetent females, indicating the possibility of reinfection in humans (Dollfus et al. 1998, Silveira et al. 2003, Kodjikian et al. 2004, Elbez-Rubinstein et al. 2009). In mouse models, reinfection occurs when parasites are of different clonal genotypes (Araújo et al. 1997, Dao et al. 2001), but no information is available on host

Financial support: FAPEMIG (CBB APQ-0521-4.01/07), CNPq (484832/2006-9)

+ Corresponding author: ricardovitor@icb.ufmg.br

Received 10 October 2008

Accepted 4 March 2009 co-infection with recombinant $T$. gondii strains, which are commonly found in Brazil (Ferreira et al. 2006, Khan et al. 2006, Dubey et al. 2007).

In this study, we report reinfection of BALB/c mice with recombinant $T$. gondii strains after prime infection with a non-virulent strain of a different recombinant genotype and the involvement of immunological components in mouse resistance to $T$. gondii.

\section{MATERIAL AND METHODS}

T. gondii strains - Three different $T$. gondii strains isolated in Brazil were used in this study. The D8 (avirulent) and $\mathrm{CH} 3$ (virulent) strains were isolated from a dog and a chicken, respectively, as described by Brandão et al. (2006). The EGS strain was isolated from a human with congenital toxoplasmosis (Vidigal et al. 2002). They differ in their recombinant genotypes according to Ferreira et al. (2006).

Experimental mice - Female Swiss mice and BALB/c mice 4-8 weeks old, weighing 18-20 $\mathrm{g}$ at the beginning of the experiments, were obtained from Centro de Bioterismo of the Instituto de Ciências Biológicas, Universidade Federal de Minas Gerais. Swiss mice were used for parasite maintenance and to obtain tachyzoites for DNA extraction. BALB/c mice were used for reinfection experiments and bioassays. The experiments conducted in this study were approved by the local Ethical Committee (UFMG protocol 038/05).

Prime infection and reinfection of mice with T. gondii - Cysts of the D8 strain of T. gondii were obtained from Swiss mice previously inoculated orally with freshly prepared brain cysts. Cysts of the EGS and $\mathrm{CH} 3$ strains were obtained from Swiss mice inoculated with brain 
cysts and orally treated with sulfadiazine for 10 days. $\mathrm{BALB} / \mathrm{c}$ mice were divided into groups of 7-10 animals and inoculated by the oral route with 20 cysts of the D8 strain. Two groups (A and B) were challenged 45 days after primary D8 infection with 20 cysts of the EGS and $\mathrm{CH} 3$ strains, respectively. Group $\mathrm{C}$, inoculated with the D8 strain but not challenged with the other strains, was kept as a control. Naive BALB/c mice were prime infected with EGS (group D) and $\mathrm{CH} 3$ strains (group E) and kept as 45-day controls. Mice from groups F and G were challenged with EGS and $\mathrm{CH} 3$ strains, respectively, 180 days after primary $T$. gondii D8 infection. Group $\mathrm{H}$ was kept as a control (mice infected only with the D8 strain). Naive BALB/c mice were prime infected with the strains EGS (group I) and CH3 (group J) and kept as 180-day controls. After challenge, the mortality of the animals was observed over 30 days. The animals that survived were sacrificed and their brains were examined for the total number of tissue cysts, bioassayed (ip inoculation of 20 brain cysts in normal BALB/c mice) according to Brandão et al. (2006) and used for DNA analysis.

Polymerase chain reaction - restriction fragment length polymorphisms (PCR-RFLP) - Genotyping was performed using the $c S 10-\mathrm{A} 6$ genetic marker to confirm reinfection of mice. This marker was chosen because it has been shown to distinguish D8 from EGS and CH3 strains (Ferreira et al. 2006). To obtain tachyzoites for DNA extraction, brain cysts of each mouse that survived after challenge were inoculated via ip into Swiss mice. Tachyzoites were harvested from the peritoneum of each mouse under aseptic conditions five-seven days after inoculation. DNA was extracted with phenol-chloroform according to Sambrook et al. (1989). The PCR-RFLP conditions were the same as those described by Ferreira et al. (2006). Amplifications were performed by using primers 5' CTGGTTACATTTTCGCCTATCA3' and 3' CCTAGTCCAAACTAGGGCTTGA5', producing a 341-bp fragment. PCR products were digested with restriction enzyme RsaI. The DNA banding pattern was resolved in 5\% polyacrylamide gels and then silver stained. The RH (type I), ME49 (type II) and VEG (type III) strains were used as references.

Tachyzoite antigen - Soluble tachyzoite antigens (STAg) were obtained as previously described (Elsaid et al. 2001). Tachyzoites of the RH strain were sonicated using five periods of $30 \mathrm{sec}$ at $40 \mathrm{hertz}$ at $1 \mathrm{~min}$ intervals. After centrifugation at $4^{\circ} \mathrm{C}(30 \mathrm{~min} / 13,000 \mathrm{~g})$, the supernatant was collected and stored in aliquots at $-20^{\circ} \mathrm{C}$ until use. Protein concentration was determined according to the Lowry method (Lowry et al. 1951).

Enzyme-linked immunosorbent assay (ELISA) Blood was collected from each mouse 45 and 180 days after primary infection with the D8 strain, immediately before challenge with the second strain. Sera were tested individually for determination of $\operatorname{Ig} \mathrm{A}, \operatorname{IgM}$ and IgG (total IgG, IgG1 and IgG2a) by ELISA, according to Elsaid et al. (2001). Microplates were coated with STAg (0,5 $\mu \mathrm{g} /$ well). Sera were diluted 1:100 (IgG) and 1:50 (IgG1, IgG2a, IgM and IgA) in PBS-Tween-20 at $0.05 \%$ (PBS-
$\mathrm{T}$ ), in duplicate, and incubated at $37^{\circ} \mathrm{C}$ for $45 \mathrm{~min}$. Peroxidase-conjugated anti-mouse IgG (or IgG1, IgG2a, IgM and IgA) (SIGMA) was added to each well. The reaction was visualised with ortho-phenylenodiamine and stopped with $4 \mathrm{~N} \mathrm{H}_{2} \mathrm{SO}_{4}$. Absorbance was read at $490 \mathrm{~nm}$ on a Microplate Reader BIORAD model 3550. A cut-off value was calculated from the mean OD +3 SD of eight noninfected control sera. Each serum sample was assayed in duplicate, taking the mean as the final result. Negative and positive controls were included on each plate.

Splenocyte cultures and cytokine measurement - Mice infected with the D8 strain were sacrificed on the 45th and 180th days post-infection and had their spleens removed. Spleens from uninfected mice were used as control. Splenocyte suspensions were washed in RPMI-1640 medium and were treated for $2 \mathrm{~min}$ with lysing buffer ( 9 volumes of $0.16 \mathrm{M} \mathrm{NH}_{4} \mathrm{Cl}$ and 1 volume of $0.17 \mathrm{M}$ Tris-HCl, $\mathrm{pH} 7.5$ ). The erythrocyte-free cells were then washed three times, adjusted to $10^{7}$ cells $/ \mathrm{mL}$ in RPMI-1640 and supplemented with $10 \%$ heat-inactivated foetal calf serum and gentami$\operatorname{cin}(40 \mathrm{mg} / \mathrm{L})$. The cell suspension was distributed in a $24-$ well tissue culture plate and cultured with STAg $(10 \mu \mathrm{g} /$ $\mathrm{mL})$, Con A (10 $\mu \mathrm{g} / \mathrm{mL})$ or RPMI medium alone for $72 \mathrm{~h}$ at $37^{\circ} \mathrm{C}$ in $5 \% \mathrm{CO}_{2}$ (Fux et al. 2003). The supernatants were subsequently collected for cytokine measurements. IL-10 and IFN- $\gamma$ were quantified in supernatants of the spleen cells using the BD OptEIA ${ }^{\circledR}$ kits, lots 57710 and 92791, respectively (BD Biosciences), according to the manufacturer's instructions. Optical density was read on a microplate reader (Spectramax Plus ${ }^{\circledR}$, Molecular Devices) and concentration was calculated in reference to a standard curve employing the respective recombinant cytokines. The assay was performed in duplicate and mean values were calculated using a standard curve as described by the manufacturer.

Statistical analysis - The statistical significance of the differences between ELISA absorbance means and the cytokine levels in the supernatants from splenocyte cultures obtained from the different mice groups was determined by the Student's $t$-test. The difference was considered statistically significant when $\mathrm{p}<0.05$.

\section{RESULTS}

Mortality, brain cysts and bioassay - Challenge with the EGS or CH3 strains (groups A and B) did not lead to death of mice 45 days after prime infection with the D8 strain (Table). The number of brain cysts in mice challenged 45 days after primary infection showed no significant differences compared to the non-challenged mice (group C). In the bioassay, mortality occurred in two out of eight $(25 \%) \mathrm{BALB} / \mathrm{c}$ mice inoculated with 20 brain cysts obtained from survivors of group A. Challenge with the EGS strain 180 days after prime infection with the D8 strain (group F) led to the death of one (11.1\%) mouse. One (10\%) out of 10 mice died when challenged with the $\mathrm{CH} 3$ strain (group G). The number of cysts in the brain of the EGS strain-challenged mice, 180 days after primary infection (group F), showed a significant difference compared to that of the non-challenged mice (group I). In the bioassay, mortality occurred in all 
TABLE

Survival, brain cysts, PCR and bioassay of BALB/c mice prime-infected with D8 strain and challenged after 45 days or 180 days with EGS or $\mathrm{CH} 3$ strains of Toxoplasma gondii

\begin{tabular}{|c|c|c|c|c|c|c|}
\hline \multirow[b]{3}{*}{ Group $^{a}$} & \multirow[b]{3}{*}{ Strains } & \multicolumn{5}{|c|}{ Challenged 45 days after prime-infection } \\
\hline & & \multicolumn{2}{|c|}{ Reinfection } & \multirow[b]{2}{*}{$\begin{array}{l}\mathrm{PCR}^{d} \\
\mathrm{~N}(\%)\end{array}$} & \multicolumn{2}{|c|}{ Bioassay of survivors } \\
\hline & & $\begin{array}{c}\text { Survival }^{b} \\
\text { N (\%) }\end{array}$ & Cyst number ${ }^{c}$ & & $\begin{array}{c}\text { Survival }^{e} \\
\mathrm{~N}(\%)\end{array}$ & $\begin{array}{c}\text { Brain cysts } f \\
\text { N }\end{array}$ \\
\hline A & $\mathrm{D} 8+\mathrm{EGS}$ & $8 / 8(100)$ & $225 \pm 122.5$ & $6 / 8(75)$ & $6 / 8(75)$ & $6 / 6$ \\
\hline $\mathrm{B}$ & $\mathrm{D} 8+\mathrm{CH} 3$ & $7 / 7(100)$ & $378.6 \pm 232.5$ & $0 / 7(0)$ & $7 / 7(100)$ & $7 / 7$ \\
\hline $\mathrm{C}$ & D8 & $8 / 8(100)$ & $262.5 \pm 138.2$ & ND & $8 / 8(100)$ & $8 / 8$ \\
\hline $\mathrm{D}$ & EGS & $0 / 10(0)$ & NS & NS & - & - \\
\hline \multirow[t]{2}{*}{$\mathrm{E}$} & $\mathrm{CH} 3$ & $0 / 10(0)$ & NS & NS & - & - \\
\hline & & \multicolumn{5}{|c|}{ Challenged 180 days after prime-infection } \\
\hline $\mathrm{F}$ & $\mathrm{D} 8+\mathrm{EGS}$ & $8 / 9(88,9)$ & $683.3 \pm 383^{g}$ & 8/8 (100) & $0 / 8(0)$ & - \\
\hline $\mathrm{G}$ & $\mathrm{D} 8+\mathrm{CH} 3$ & $9 / 10(90)$ & $366.7 \pm 150$ & $6 / 9(66.7)$ & 9/9 (100) & $9 / 9$ \\
\hline $\mathrm{H}$ & D8 & $10 / 10(100)$ & $327.8 \pm 132^{g}$ & ND & $10 / 10(100)$ & $10 / 10$ \\
\hline I & EGS & $0 / 10(0)$ & NS & NS & - & - \\
\hline $\mathrm{J}$ & $\mathrm{CH} 3$ & $0 / 10(0)$ & NS & NS & - & - \\
\hline
\end{tabular}

$a$ : groups A and B: mice challenged with EGS or CH3 strain, respectively, 45 days after primary D8 infection; groups C, D and E: mice prime-infected with D8, EGS and CH3 strains, respectively (45-day controls); groups F and G: mice challenged with EGS or CH3 strains, respectively, 180 days after primary D8 infection; groups H, I and J: mice prime-infected with D8, EGS and CH3 strains (180-day controls). After challenge, mortality of animals was observed over 30 days. The experiment was repeated twice and provided similar results; $b$ : number of survivors out of the total number of mice challenged; $c$ : number of brain cysts evaluated at 30 days post challenge; $d$ : number of mice presenting the two strains (positive PCR at $c S 10$-A6 locus) out of the total number of survivors after challenge; $e$ : number of survivors out of the total number of animals bioassayed; $f$ number of mice with brain cysts out of the total number of mice bioassayed; $g$ : significant difference between mice challenged with the EGS strain, 180 days after primary infection, with the D8 strain 180-day controls, $\mathrm{p}<0,05$; ND: not done; NS: no survival.

BALB/c mice inoculated with 20 brain cysts obtained from survivors of group F (EGS strain). All mice that were prime infected with only the EGS or $\mathrm{CH} 3$ strains (groups D, E, I and J) died before 30 days of infection.

Genotyping of T. gondii by PCR-RFLP - Analysis carried out with the marker $c S 10-\mathrm{A} 6$ in the DNA samples of $T$. gondii showed the co-existence of the strains D8 and EGS in $75 \%$ of mice challenged at 45 days after prime infection (Table). In the mice challenged 180 days after prime infection, DNA analysis showed that $100 \%$ of the surviving animals were reinfected with EGS and $66.7 \%$ were reinfected with $\mathrm{CH} 3$. Representative results of PCR-RFLP analysis of $T$. gondii DNA from mice challenged with EGS strain are shown in Fig. 1.

Antibodies to T. gondii - Successful prime infection with the D8 strain was confirmed by ELISA in all the $\mathrm{BALB} / \mathrm{c}$ mice inoculated. A slight yet significant increase was observed in IgA and IgG1 antibodies 180 days after prime infection with the D8 strain, compared to the animals at 45 days of infection with the same strain $(\mathrm{p}<0.05)$ (Fig. 2).

Cytokine measurement - Our experiments demonstrated high levels of IFN- $\gamma$ and IL-10 at 45 and 180 days post-infection (Fig. 3). Increase in the production of IL-10 was significantly higher in BALB/c mice after 180 days of infection with the D8 strain, compared to 45 days infected mice $(\mathrm{p}<0.05)$.

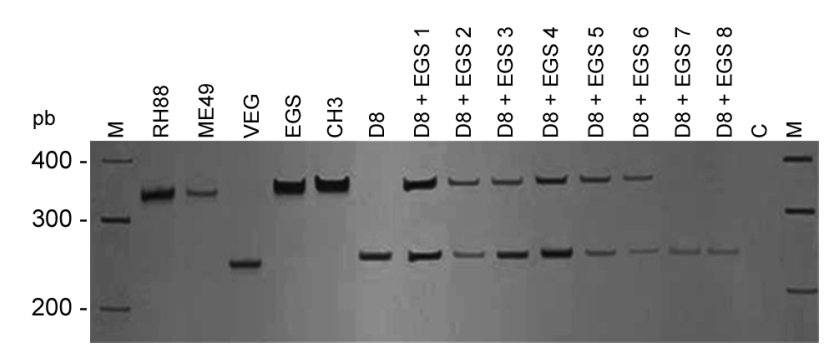

Fig. 1: polymerase chain reaction-restriction fragment length polymorphism of Toxoplasma gondii at cS10-A6 locus with restriction endonuclease $R s a \mathrm{I}$ in $5 \%$ polyacrylamide gel silver stained to verify reinfection of BALB/c mice challenged with the EGS strain, 45 days after primary D8 strain infection. RH (Type I), ME49 (Type II) and VEG (Type III) strains were used as reference. D8 + EGS: eight mice challenged with the EGS after primary D8 infection; M; molecular weight marker (Promega $100 \mathrm{pb}$ ); C: negative control, without DNA. The experiment was repeated twice and provided similar results.

\section{DISCUSSION}

When BALB/c mice were prime infected with the avirulent D8 strain of $T$. gondii and challenged after 45 or 180 days with the virulent EGS or CH3 strains, the mortality rate significantly decreased when compared with the mortality of mice infected only with the strains used in the challenge. This likely occurred as a consequence of the adaptive immune response conferred by 


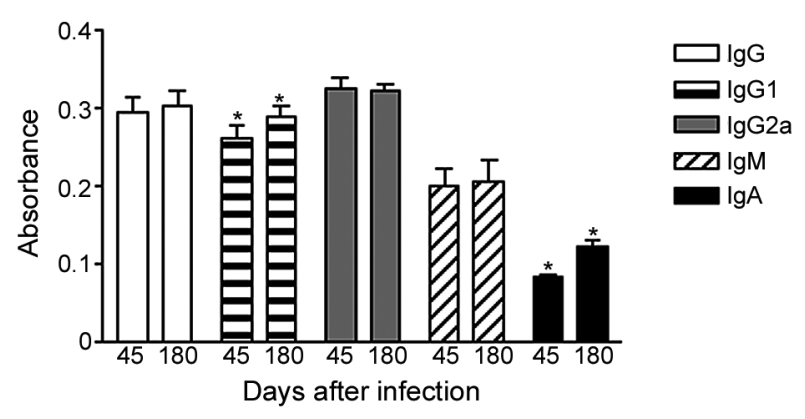

Fig. 2: specific IgG, IgG1, IgG2a, IgM and IgA antibodies to Toxoplasma gondii detected by enzyme linked immunosorbent assay in plasma of BALB/c mice at 45 and 180 days after infection with the D8 strain before challenge with the second strain. The experiment was repeated twice and provided similar results. Cutoff values (mean OD $+3 \mathrm{SD}$ ) were $\operatorname{IgG}=0,032, \operatorname{IgG} 1=0,021, \operatorname{IgG} 2 \mathrm{a}=0,040, \operatorname{IgM}=0,019$ and $\operatorname{IgA}=0,013$. Non-infected controls presented absorbance values bellow cutoff values (data not showed). Asterisks means significant difference between IgG1 or IgA antibodies 180 days after primeinfection with the D8 strain, compared to the animals at 45 days of prime-infection, $\mathrm{p}<0.05$.
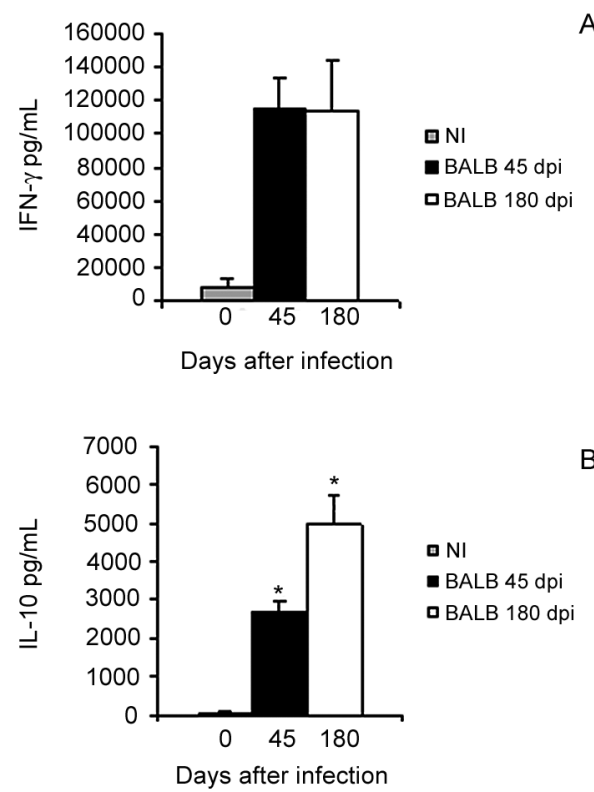

Fig. 3: levels of IFN- $\gamma$ (A) and IL-10 (B) in BALB/c mice orally infected with 20 cysts of the D8 Toxoplasma gondii strain on days 0 (NI: non infected), 45 (BALB $45 \mathrm{dpi}$ ) and 180 (BALB $180 \mathrm{dpi}$ ) post infection. IFN- $\gamma$ and IL-10 were measured in the supernatant of splenocytes cultured with STAg. Results obtained in the supernatant of splenocyte cultured with Con A or RPMI medium alone are not shown. The values shown are the means of eight animals. The experiment was repeated twice and provided similar results. Asteriks means significant difference in the production of IL-10 after 180 days of infection with the D8 strain compared with 45 days of infection $(\mathrm{p}<0.05)$.

the D8 strain. The increased number of brain cysts after challenge with the EGS strain supports the coexistence of the D8 and EGS strains 180 days after prime-infection (683.3 \pm 383 versus $327.8 \pm 132$ cysts). A bioassay con- firmed reinfection in two of eight (25\%) survival mice challenged with the EGS strain, 45 days after prime infection. PCR-RFLP showed a higher efficiency in reinfection confirmation (6 out of $8 ; 75 \%$ of positive results). The coexistence of D8 and EGS (180-day challenge group) was confirmed in the surviving mice by $100 \%$ mortality after a bioassay and a $100 \%$ positive PCRRFLP. Ninety percent and $88.9 \%$ survival after challenge with $\mathrm{CH} 3$ and EGS, respectively, 180 days after primary infection suggests a partial loss of protective immunity after that period of time. PCR-RFLP did not show coexistence of the $\mathrm{D} 8$ and $\mathrm{CH} 3$ strains in the brain of mice challenged at 45 days after prime infection. The challenge 180 days after prime infection resulted in the coexistence of D8 and EGS strains in all the surviving mice. Coexistence of D8 and $\mathrm{CH} 3$ strains was confirmed in $66.7 \%$ of the surviving mice. The presence of two clonal lines of $T$. gondii in the brain of mice after experimental reinfection was previously demonstrated by Dao et al. (2001). These authors observed that primary infection with the Prußgal T. gondii strain did not impair tissue cyst formation upon reinfection with the Ned strain of $T$. gondii, which belongs to another $T$. gondii clonal genotype. Our work, in turn, showed for the first time the possibility of experimental reinfection with recombinant strains of $T$. gondii.

The amount of IFN- $\gamma$ produced by splenocytes obtained 45 days after D8 strain infection was not different from that produced 180 days after the infection. On the other hand, the significantly higher amount of IL-10 produced at 180 days after primary infection is likely associated with the higher susceptibility to reinfection by $T$. gondii. According to Wilson et al. (2005), IL-10 plays an important role in the balance between protective immunity and the development of immune pathology in toxoplasmosis. These authors also showed that mice deficient in this cytokine develop a lethal acute inflammatory response. In the present work, the higher amount of IL-10 in BALB/c mice 180 days after infection with the D8 strain was probably one of the factors that favoured the higher mortality observed after challenge with the EGS and $\mathrm{CH} 3$ strains. Although allowing the survival of the host infected with $T$. gondii during a primary infection, IL-10 could contribute to reinfection and higher mortality in the event of subsequent challenge. This probably occurs because IL-10 would act to inhibit initial events of inflammation, crucial in protecting the host during infection with $T$. gondii. Thus, the higher production of IL-10 in the mice at 180 days after the prime infection with the D8 strain may have contributed to the reinfection of these animals with the $\mathrm{CH} 3$ strain and may also have increased the infection rate with the EGS strain.

The significant, though slight increase of $\operatorname{IgA}$ and IgG1 in BALB/c mice prime infected at 180 days with the D8 strain may also be associated with higher susceptibility to reinfection by $T$. gondii. These results corroborate the hypothesis that an immune inflammatory response was less exacerbated in BALB/c mice challenged 180 days after prime infection with the D8 strain, favouring reinfection by $T$. gondii. According to Correa et al. (2007), IgA production in mice is stimulated by the 
presence of the cytokines IL-10 and TGF- $\beta$, while IgG1 is a chronic phase marker whose production is stimulated mainly by IL-4, which is related to a Th2 response.

Our work has shown for the first time the occurrence of reinfection of BALB/c mice with $T$. gondii recombinant strains that are commonly found in Brazil (Ferreira et al. 2006). The $\mathrm{D} 8$ recombinant strain was capable of inducing a protective immune response in mice reinfected by $T$. gondii, ensuring survival up to $100 \%$ though not preventing reinfection. The occurrence of reinfection varied in function by the parasite strain used in the challenge and by the time after prime infection when the challenge was performed. These observations led us to conclude that the occurrence of reinfection is related not only to the genotype of the strain, as previously reported by others (Araújo et al. 1997, Dao et al. 2001), but also to the immune response of the host, which is dependent on the time of the infection.

\section{ACKNOWLEDGMENTS}

To Rosalida Estevan Nazar Lopes, for her technical assistance. RWAV is a CNPq Research Fellow.

\section{REFERENCES}

Araújo F, Slifer T, Kim S 1997. Chronic infection with Toxoplasma gondii does not prevent acute disease or colonization of the brain with tissue cysts following reinfection with different strains of the parasite. J Parasitol 83: 521-522.

Brandão GP, Ferreira AM, Melo MN, Vitor RWA 2006. Characterization of Toxoplasma gondii from domestic animals from Minas Gerais, Brazil. Parasite 13: 143-149.

Buzoni-Gatel, D, Schulthess, J, Menard, LC, Kasper, LH 2006. Mucosal defenses against orally acquired protozoan parasites, emphasis on Toxoplasma gondii infections. Cell Microbiol 8: 535-544.

Correa D, Cañedo-Solares I, Ortiz-Alegría LB, Caballero-Ortega H, Rico-Torres CP 2007. Congenital and acquired toxoplasmosis: diversity and role of antibodies in different compartments of the host. Parasite Immunol 29: 651-660.

Dao A, Fortier B, Soete M, Plenat F, Dubremetz JF 2001. Successful reinfection of chronically infected mice by a different Toxoplasma gondii genotype. Int $J$ Parasitol 31: 63-65.

Dollfus H, Dureau P, Hennequin C, Uteza Y, Bron A, Dufier JL 1998. Congenital Toxoplasma chorioretinitis transmitted by preconceptionally immune women. Br J Ophthalmol 82: 1444-1445.

Dubey JP, Sundar N, Gennari SM, Minervino AHH, Farias NAR, Ruas JL, Santos TRB, Cavalcante GT, Kwok OCH, Su C 2007. Biologic and genetic comparison of Toxoplasma gondii isolates in free-range chickens from the Northern Pará state and Southern state of Rio Grande do Sul, Brazil revealed highly diverse and distinct parasite populations. Vet Parasitol 143: 182-188.

Elbez-Rubinstein A, Ajzenberg D, Dardé ML, Cohen R, Dumètre A, Yera H, Gondon E, Janaud JC, Philippe Thulliez P 2009. Congen- ital toxoplasmosis and reinfection during pregnancy: case report, strain characterization, experimental model of reinfection, and review. J Infect Dis, 199: 280-285.

Elsaid MM, Martins MS, Frézard F, Braga EM, Vitor RWA 2001. Vertical toxoplasmosis in a murine model. Protection after immunization with antigens of Toxoplasma gondii incorporated into liposomes. Mem Inst Oswaldo Cruz 96: 99-104.

Ferreira AM, Vitor RWA, Gazzinelli RT, Melo MN 2006. Genetic analysis of natural recombinant Brazilian Toxoplasma gondii strains by multilocus PCR-RFLP. Infect Genet Evol 6: 22-31.

Filisetti D, Candolfi E 2004. Immune response to Toxoplasma gondii. Ann Ist Super Sanita 40: 71-80.

Fux B, Rodrigues CV, Portela RW, Silva NM, Su C, Sibley D, Vitor RWA, Gazzinelli RT 2003. Role of cytokines and major histocompatibility complex restriction in mouse resistence to infection with a natural recombinant strain (type I-III) of Toxoplasma gondii. Infect Immun 71: 6392-6401.

Gazzinelli R, Xu, Y, Hieny S, Cheever A, Sher A 1992. Simultaneous depletion of CD4+ and CD8+ T lymphocytes is required to reactivate chronic infection with Toxoplasma gondii. J Immunol 149: $175-180$.

Gellin BG, Soave R 1992. Coccidian infection in AIDS - toxoplasmosis, cryptosporidiosis, and isosporiasis. Med Clinics North Am 76: 205-234.

Khan A, Jordan C, Muccioli C,Vallochi AL, Rizzo LV, Belfort RJ, Vitor RWA, Silveira C, Sibley LD 2006. Genetic divergence of Toxoplasma gondii strains associated with ocular toxoplasmosis, Brazil. Emer Infec Dis 12: 942-949.

Kodjikian L, Hoigne I, Adam O, Jacquier P, Aebi-Ochsner C, Aebi C, Garweg JG 2004. Vertical transmission of toxoplasmosis from a chronically infected immunocompetent woman. Pediatr Infect Dis J 23: 272-274.

Lowry OH, Rosebrough NJ, Farr AL, Randall RJ 1951. Protein measurement with the Folin phenol reagent. J Biol Chem 193: 265-275.

Sambrook J, Fritsch EF, Maniatis T 1989. Molecular cloning. A laboratory manual (2nd ed.), Cold Spring Harbor Lab, New York, p. 6.36-6.48.

Silveira C, Ferreira R, Muccioli C, Nussenblatt R, Belfort RJ 2003. Toxoplasmosis transmitted to a newborn from the mother infected 20 years earlier. Am J Ophthalmol 136: 370-371.

Subauste CS, Koniaris AH, Remington JS 1991. Murine CD8+ cytotoxic T Lymphocytes lyse Toxoplasma gondii-infected cells. $J$ Immunol 147: 3955-3959.

Suzuki Y, Conley FK, Remington JS 1989. Importance of endogenous IFN-gamma for prevention of toxoplasmic encephalitis in mice. $J$ Immunol 143: 2045-2050.

Vidigal PV, Santos DV, Castro FC, Couto JC, Vitor RWA, Brasileiro Filho G 2002. Prenatal toxoplasmosis diagnosis from amniotic fluid by PCR. Rev Soc Bras Med Trop 35: 1-6.

Wilson EH, Wille-Reece U, Dzierszinski F, Hunter CA 2005. A critical role for IL-10 in limiting inflammation during toxoplasmic encephalitis. J Neuroimmunol 165: 63-74. 